\title{
A Study on the Prospects of the Korea Beauty Industry
}

\author{
Hye-JinKwon**1, Hee-KyungLim ${ }^{2}$ \\ ${ }^{*}$ Professor, Department of Chemical Engineering, Soongsil Univ., Seoul, Republic of Korea \\ ${ }^{2}$ Professor, Department of Beauty Arts, Seokyeong Univ., Seoul, Republic of Koreakwonhj0070@ssu.ac.kr ${ }^{* 1}$, \\ haidylim@gmail.com ${ }^{2}$
}

Article History: Received: 11 January 2021; Accepted: 27 February 2021; Published online: 5 April 2021

\begin{abstract}
The development of IT industry is playing an important role in the prevention of the COVID-19 infection in Korea. The development of IT industry is used in various fields. The beauty industry in the era of the 4th Industrial Revolution can identify the racial, regional and individual characteristics of customers through the use of big data with the AI system. It is also expected that such development will bring a change in the creation of new jobs and occupations in the service industry. Therefore, it is necessary to establish an environment that enables the development of nurturing education and creativity of outstanding individuals who will lead new business trends. In addition, a beauty-related industry that can meet the desire of new elderly consumers throughout the society is required. It is expected that the beauty industry in Korea will require a service that combines self-development, convenience and plays for companies, workers and consumers in future.
\end{abstract}

Keywords: AI, beauty industry in Korea, K-beauty, SNS, big data, IoT

\section{Introduction}

Our modern society is changing rapidly. The face recognition system mainly used in public institutions enriches personal life due to the development of AI. Due to the development of IT industry, things give people life convenience but jobs are reduced or lost or new jobs are created through the automation and mechanization since the 4th Industrial Revolution. A change in the business environment also appears in beauty-related services and the manufacturing industry in order to offer convenience for modern people who are busy due to continuous industrial development.

\section{Development of the $4^{\text {th }}$ Industry}

The development of the 4th Industrial Revolution brings a change to everyday life. The vacuum cleaners, automobiles and mobile phones used in everyday life were simple functional machines and these machines were operated manually in the past. However, all things are connected to the sensors and Internet that is a communication technology in IoT so that such things directly handle tasks that were previously done by people in the past by the delivery of a voice command.

The size of big data and cloud which is a vast network of remote servers distributed around the whole world cannot be defined simply. Such big data and cloud can be accessed from a device that supports Internet through the Internet without a physical server, so people can share and use necessary information at anytime and anywhere.

The World Economic Forum presents the constantly changing 4th Industrial Revolution [1] as the connection structure shown in Figure 1.The 4th Industrial Revolution is the combination of an offline world in real life established by the 1st and 2nd Industrial Revolutions and a virtual online world established based on the 3rd Industrial Revolution which is a digital revolution. The 1st Industrial Revolution is the hydraulic power and vapor-based manufacturing revolution based on mechanization and the 2nd Industrial Revolution is the mass production basedon electricalenergy. The 3rd Industrial Revolution is the information technology revolution of computer and Internet.Figure 2 below shows a change in the industrial revolution[2].

\section{A Chang in the Service of Beauty Industry in Korea}

The booking service through the customer management system is the representative example of industrialization in the service industry. The service is gradually shifting from the previous telephone booking to the establishment of booking system using a smartphone. In the past, customers waited in a limited place. But now customers can check their waiting status in real time through their smartphone. The real-time wait list and the waiting time alert information provided at service places offer convenience for customers to use their time. The service system allows customers to check their waiting status through the service web so that they can spare time separately. A variety of information including self measurementand product recommendation based on individual preference through the use of a smartphone or a web book are also introduced for potential customers. 


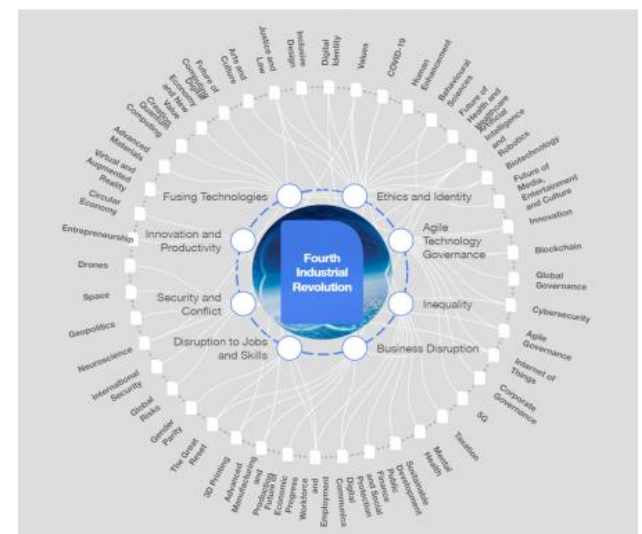

Figure $1.4^{\text {th }}$ Industrial Revolution

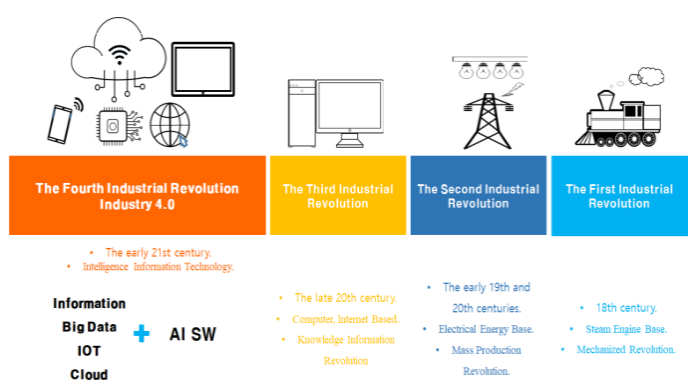

Figure 2. A Change in the Industrial Revolution

\subsection{AI Skin Care Service}

It is not required to make a part of the human body to come into direct contact with the recognition device for face care. AI scans a human face through a camera for face recognition. The face recognition is divided into the statistical recognizer based on an error function and the recognizer using the neural network, and the characteristics for face recognition are divided into geometric characteristics, high-density map and texture characteristics[3].The 'Beauty Concierge' project combining Amore Pacific's beauty and IT technologies using human body data introduced the 'Skin Finder' shown in Figure 3 which was the exclusive mobile skin diagnosis service to the Amore Pacific mall. The 'Skin Finder' is the skin diagnosis system based on IT technologies. The services including the skin analysis using a mobile phone camera, products and management are applied so that users can receive information of their skin type, tips on beauty, contents and the solution and product suggestion based on their individual result $[4,15]$. Also,IOPE's 'Tailored 3D mask' shown in Figure 3, the 3D printing tailored mask pack, is the service that the face structure and size are measured using the latest 3D technology at a shop and the hydro gel mask pack is produced and provided on the spot using a 3D printer [5].The AI beauty store "ON and the Beauty" adopts an operation method based on big data which is differentiated from existing drug stores and select shops. The "AI Beauty Store" shown in Figure 4which is the AI-based skin care solution provides the 3-step AI skin care system service including AI face capturing, skin analysis and product recommendation[6].

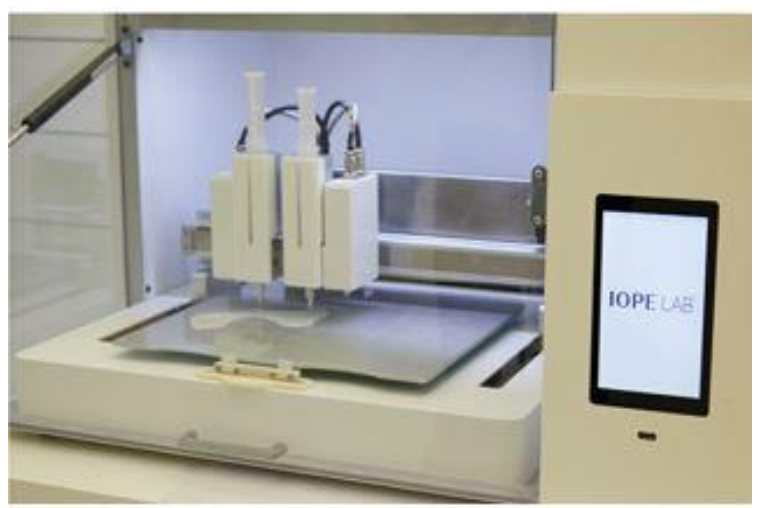


Figure 3. Skin Finder \& Tailored 3D Mask [4, 5]

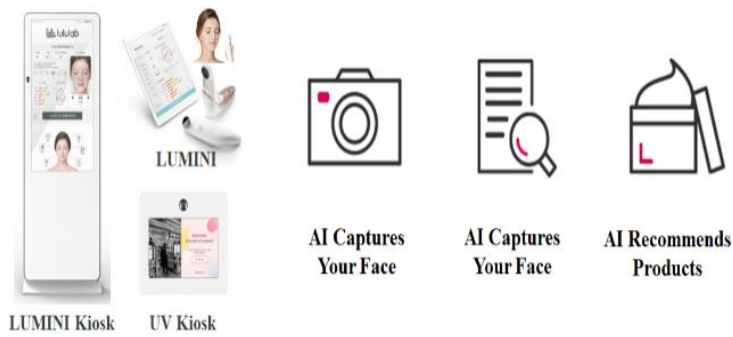

Figure 4. 3-Step AI Skincare [6]

\subsection{Makeup \& Hair Industry}

A visible effect is important for makeup and hair in the beauty industry. The virtual makeup application on the smartphone allows users to complete their makeup through indirect experience, so product manufacturers can promote their products to consumers. The makeup application using the AR technology reproduces the makeup that fits the skin color and the face shape virtually through the face recognition program, so the users can experience a sense of immersion through the image interface that enables interaction [7]. This program allows users to view various makeup styles and colors applied virtually to their face through an image in advance [7,8]. Amore Makeup provides the AI makeup simulation service implemented in the smartphone through the cooperation with Samsung Electronics since 2018

Many smartphone virtual experience applications including mise en scene which is a professional hair product company are used for hair styles. These applications allow users to select and apply a hair style and a hair color to their face virtually.

In addition, users can also download and use other makeup and hair applications developed by the general public freely using their smartphone.

In light of the trends calling for adopting the correct transition in the Iraqi economy from a planned central

\subsection{Nail Industry}

Previously, nail service workers provided various nail services including basic care of fingernails, toenails, manicure, pedicure, art nail and 3D nail to customers. However, due to the appearance of automated nail equipment, customers can receive nail care within a shorter period of time. When the basic nail management and the basecoat process are performed by a service worker, the 'aura eznail 3' product shown in Figure 5 recognizes the area for the nail service automatically. When a design is selected according to a personal taste, the nail product is applied to the nail automatically. This product reduces the work time so that the nail art can be completed within 20 seconds andvarious design expressions and easy operation are possible. [9].

\subsection{Effect of the $4^{\text {th }}$ Industrial Revolution on jobs in the Beauty Industry in Korea}

The 4th Industrial Revolution is the human-centered revolution that combines real and virtual worlds created by the 1st, 2nd and 3rd Industrial Revolutions. Smartphone and tablet PCs based on mobile Internet are important means to communicate with and recognize the world. Rapid development of IoT (internet of things) enables that all things from manufacturing facilities and infrastructure to health care are equipped with a sensor and an actuator for data collection, remote monitoring, decision making and the optimization of manufacturing processes. The number of opportunities for the development of IoT is infinite.

Flexibility and quickness through the connection and convergence, continuous education and skill acquisition are necessary to catch up with the latest trend and technologies. Ken Robinson who was a creativity expert spoke in the TED lecture as follows. The current school education kills creativity. The key to creativity is to understand ourselves as much as possible. A creative talent finds a creative element beyond existing elements [10].

Tony Wagner who is the author of "Creating Innovators" asserted that four attributes of a talent who would change the world included first, a habit to raise a question, in-depth understanding and curiosity for demand, second, acquisition of knowledge in a different viewpoint as an expert and collaborative work, third, comprehensive or integrated thinking method, and fourth, behavior of experiment-oriented character [11]. 
Inhwa Lee who is the author of "The 4th Industrial Revolution in Korea" asserted "The 4th Industrial Revolution does not reduce jobs. It just changes the form of jobs just as the previous industrial revolutions. Labor is transferred to robots so that human tasks are advanced into a combination of creative tasks and plays." [12]. He expected in the "Deep Shift Technology Tipping Points and Societal Impact" that the following tipping points would occur during the period between 2018 and 2027 as shown in Figure 6[13].

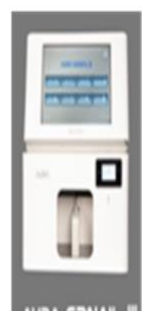

NRI EZNAL II

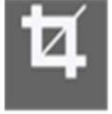

Stable design

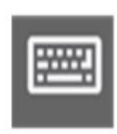

Easy operation

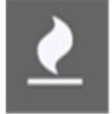

Diverse and unique designs

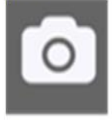

Self-camera

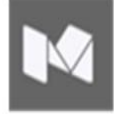

UI design

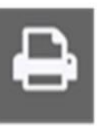

HP Printer

Module

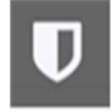

No harm to the human body.

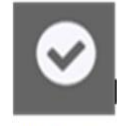

HP Printer

Module

Figure 5. Function of aura eznail 3 nail art system [9]

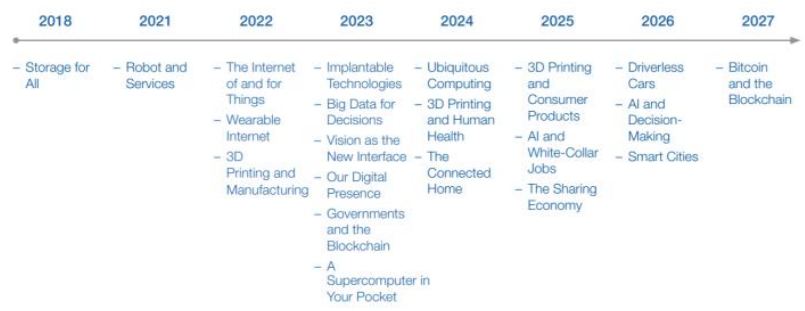

Figure 6. Average Year Each Tipping Point is Expected to Occur [13]

The beauty industry in Korea as one of the most advanced Internet nations in the world is changing rapidly due to the use of PC, tablets and smartphone that can access Internet as well; as IT such as IoT, cloud, big data and AI. Also, people's space convergence information of humans is shared through their individual smart devices. The preference according to the age group of customers or articles used by individuals is an indicator of big data using IT and the personal preference of the general public as well as the purchase behavior and preference of customers from a new discovery can be analyzed.In this era of the 4th Industrial Revolution, we make new technological assets more durable and flexible while data and analysis can change a method to maintain such assets. The smartphone platform gathers people, assets and data and creates a completely new method to consume products and services in such process [14].

Accordingly, companies can accumulate people, assets and data, prepare and plan a tailored beauty industry.

\section{Conclusions}

The beauty industry can identify the racial, regional and individual characteristics of customers through the use of big data with the AI system. IoT provides customized feedbacks and services to customers, and when the satisfaction with products is raised, companies can establish customized basis to reduce costs related to the loss and distribution for stock. Big data and AI used in the future beauty industry enrich personal life. However, it is expected that such development will bring a change in the creation of new jobs and occupations in the service industry. It is also necessary to establish an environment that enables the development of nurturing education and creativity of outstanding individuals who will lead new business trends. In addition, a beauty-related industry that can meet the desire of new elderly consumers throughout the society is required. It is expected that the beauty industry in Korea will require a service that combines self-development, convenience and plays for companies, workers and consumers in future.

\section{Acknowledgment}

This research was supported by 2018 Basic Science Research Program through the National Research Foundation of Korea funded by the Education, Science and Technology. (No.2018008274)

\section{References}

1. Feetham, H.J., Jeong, H.S., McKesey, J., Wickless, H., Jacobe, H. (2018). Skin care and cosmeceuticals: Attitudes and trends among trainees and educators. J Cosmet Dermatol., 17(2), 220-226. 
2. Hoffmann, D. S., Dancing, D., Rosenbaum, M. (2019). Massage and Medicine: An Interprofessional Approach to Learning Musculoskeletal Anatomy and Enhancing Personal Wellness. Acad Med 94(6), 885-892.

3. Hacklin, F., Marxt, C., \& Fahrni, F. (2009). Coevolutionary cycles of convergence: An extrapolation from the ICT industry, Technological Forecasting and Social Change, 76(6), 723736.

4. Amore Pacific introduces the mobile skin diagnosis system 'Skin Finder' [Image on internet]. Amore pacific 2020 [updated 2020 Jul 30; cited 2020 Aug 7]. Available from: https://www.apgroup.com/int/ko/news/2020-07-30-1.html.

5. IOPE targets the era of tailored cosmetic products with the tailored 3D mask [Image on internet]. World Economic Forum; 2020 [updated 2020 Mar 16; cited 2020 Jul 20]. Available from: https://www.apgroup.com/int/ko/misc/news/2020-03-16.html/(website).

6. 3-Step AI Skincare[Image on internet].IuIulab 2020 [updated Unable to verify;cited 2020 Jul 20]. Available from:http://www.lulu-lab.com/en/.

7. Ernst, H. (2003). Patent information for strategic technology management, World Patent Information, 25(1), 233-242.

8. Lea, J. (2018). Understanding therapeutic massage as a form of bodywork: knowing and working on the(energy) body. Sociol Health Illn, 41(1), 180-195.

9. Aura Cosmetics [updated Unable to verify; cited 2029 Jul 20]. Available from:http://www.auracosmetics.co.kr/skin/page/product_eznail3 ko.html.

10. Min, J., Kim, Y., Lee, S., Jang, T. W., Kim, I., Song, J. (2019), TheFourth Industrial Revolution and Its Impact on Occupational Health and Safety, Worker's Compensation and Labor Conditions. Saf Health Work. 10(4), 400-408.

11. Niki, M. (2014). Adaptation of the CARE Guidelines for Therapeutic Massage and Bodywork Publications: Efforts to Improve the Impact of Case Reports. Int J Ther Massage Bodywork. Sep 3, 7(3):32-40.

12. Plakornkul, V., Vannabhum, M., Viravud, Y., Roongruangchai, J., Mutirangura, P., Akarasereenont, P., Laohapand, T. (2016). The effects of the court-type Thai traditional massage on anatomical relations, blood flow, and skin temperature of the neck, shoulder, and arm BMC Complement. Altern Med. 15(1), 16:363

13. Deep Shift:Technology Tipping Points and Societal Impact. Average Year Each Tipping Point Is Expected to Occur. [Image on internet]. 2015 [updated 2015 Sept 9; cited 2020 Aug 7]. Available from: https://www.weforum.org/reports/deep-shift-technology-tipping-points-and-societal-impact.

14. Viravud, Y., Apichartvorakit, A., Mutirangura, P., Plakornkul, V., Roongruangchai, J., Vannabhum, M., Laohapand, T., Akarasereenont, P. (2017). The anatomical study of the major signal points of the court-type Thai traditional massage on legs and their effects on blood flow and skin temperature. J Integr Med, 15(2):142-150.

15. Maluleke, W., \& Dlamini, S. (2019). The Prevalence Of Organised Cross-Border Crimes In South Africa: A Non-Empirical Statistical Data Analysis On Stock Theft And Hijacking Of Motor Vehicles. The International Journal of Social Sciences and Humanity Studies, 11(1), 116-145. 